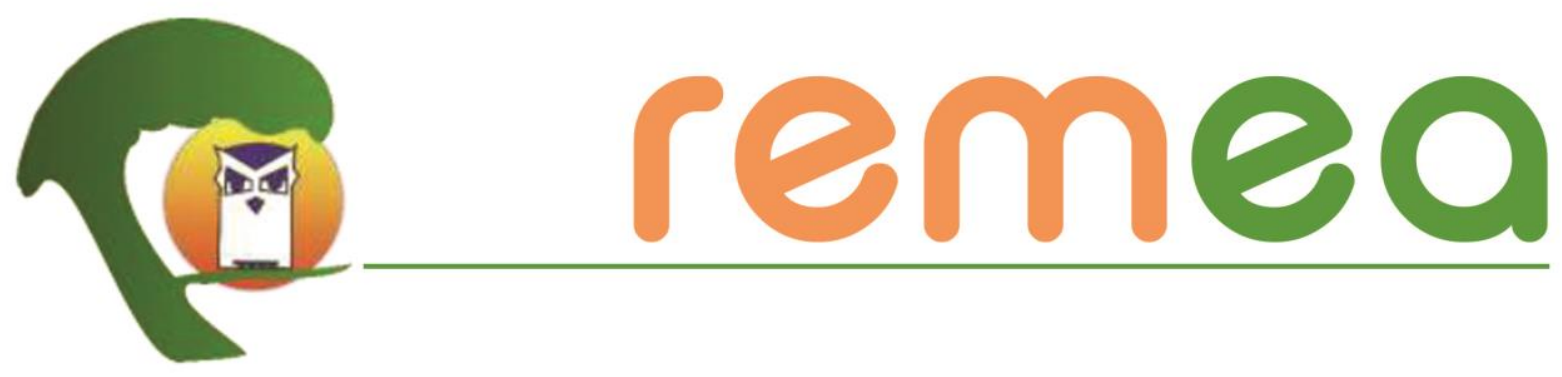

\title{
Produções da máquina desejanteambiental na composição de currículos
} nômades

\author{
Helen Moura Pessoa ${ }^{1}$ \\ Universidade Federal do Espírito Santo \\ ORCID: https://orcid.org/0000-0003-0106-3735
}

Resumo: Este texto busca ressaltar uma educação ambiental decolonial como máquina desejante, que pode produzir subjetivações, promover agenciamentos e criar novas perspectivas de vida e de relações. Ao buscar pelas produções dessa máquina nas instituições de ensino, a pesquisa encontra possibilidades nos estudos em conexão com as comunidades-escolas-universidades (como uma rede indissociável). Assim, problematiza as potências que esses estudos podem promover nos currículos e em nossas pesquisas. Nas considerações, ressalta que as produções/pesquisas podem criar reexistências nas novas potências de agir, sentir, imaginar e pensar, sugerindo a invenção de currículos nômades, que se abrem aos agenciamentos ecocomunitários nas possíveis tentativas de recriar a capacidade de pensar e agir juntos.

Palavras-chave: Educação Ambiental, Decolonialidade, Currículo.

\section{Producciones de la máquina deseante ambiental en la composición de currículos nómades}

Resumen: Este texto busca resaltar una educación ambiental decolonial como máquina deseante, que pueda producir subjetivaciones, promover agenciamientos y crear nuevas perspectivas de vida y de relaciones. Al buscar por las producciones de esa máquina en las instituciones de enseñanza, la pesquisa encuentra posibilidades en los estudios en conexión con las comunidades-escuelas-universidades (como una red indisociable). Así, problematiza las potencias que esos estudios pueden promover en los currículos y en nuestras pesquisas. En las consideraciones, se resalta que las producciones/pesquisas pueden crear re-existencias en las nuevas potencias de actuar, sentir, imaginar y pensar, sugiriendo la invención de currículos nómades, que se abren a los agenciamientos eco-comunitarios en las posibles tentativas de recrear la capacidad de pensar y actuar juntos.

Palabras-clave: Educación ambiental, Decolonialidad, Currículo.

\footnotetext{
${ }^{1}$ Doutora em Educação (PPGE/UFES) e Professora do Departamento de Química e Física no Centro de Ciências Exatas, Naturais e da Saúde (DQF/CCENS/UFES). E-mail: helen.brandao@ufes.br.
} 


\title{
Productions of the environmental desiring machine in the composition of nomadic \\ curricula
}

\begin{abstract}
This paper aims to emphasize decolonial environmental education as a desiring machine, which can produce subjectivation, promote agency and create new perspectives on life and relationships. By searching for the productions of this machine in educational institutions, the research finds possibilities in studies in connection with the communities-schools-universities (as an inseparable network). Thus, it problematizes the potentialities that these studies can promote in curricula and in our research. In its considerations, this study emphasizes that the productions/research can create re-existences in the new potentialities of acting, feeling, imagining and thinking, suggesting the invention of nomadic curricula, which are open to eco-community agencies in possible attempts to recreate the capacity to think and act together.
\end{abstract}

Keywords: Environmental education, Decoloniality, Curricula.

\section{Introdução}

Enquanto tecemos este texto, o mundo é atravessado por vários acontecimentos todos imbricados maquinicamente - como a exploração socioambiental com desmonte das políticas públicas em vários países, a emergência climática e a pandemia pelo novo coronavírus. ${ }^{2}$ Crises que foram engendradas ao longo do tempo por máquinas colonizadoras, que buscam subtrair e suprimir os desejos, ${ }^{3}$ utilizando suas engrenagens midiáticas de controle.

Não queremos com isso tentar justificar ou negar a gravidade de tais crises, pelo contrário. Trata-se de uma denúncia: a exploração sem limites da rede socioambiental, o que inclui humanos, animais e natureza imbricados - que Stengers (2015) nomeia "Gaia" -, trouxenos consequências desastrosas, que foram amplamente divulgadas por vários cientistas e ativistas ao longo de vários anos. ${ }^{4}$ A negação de todas essas evidências é que faz parte de um projeto de captura, controle dos corpos e ampliação do poder dos governos sobre essa rede.

\footnotetext{
${ }^{2}$ O novo coronavírus é uma zoonose que pode ter surgido, segundo a Organização Mundial da Saúde (OMS), no final de 2019, no mercado de Wuhan (China), onde se comercializam animais silvestres vivos ou abatidos, o que é uma das maiores suposições de contágio do vírus para os humanos, causando severa síndrome respiratória aguda (SARS-CoV-2). Esse vírus se espalhou rapidamente para as províncias chinesas e, em 1 ㅇ de março de 2020, chegou a 58 outros países (Ll et al., 2020). Em 11 de março de 2020, a OMS decreta a pandemia de coronavírus (causador da COVID-19), cobrando ações imediatas dos governos (WHO, 2020).

${ }^{3}$ Segundo Deleuze e Guattari (2011), o desejo não deve ser submetido à falta de algo, pois ele é por si só produtor, é máquina e afirmam: "[...] o desejo, tomado na ordem real da sua produção, comporta-se como fenômeno molecular desprovido de objetivo e intenção" (p. 454), pois, para os autores, "[...] o ser objetivo do desejo é o real em si mesmo" (p. 43). De acordo com os autores, todos nós possuímos objetos parciais do que desejamos, almejando que eles se tornem reais.

${ }^{4}$ Como os relatórios do Painel Intergovernamental sobre Mudanças Climáticas (IPCC) e pesquisas científicas publicadas em periódicos de reconhecimento mundial. Dentre eles, destacamos: o quarto relatório do IPCC (publicado em 2007) que alertava sobre os incêndios florestais de grande escala na Austrália - que ocorreram no
} 
Nesse contexto de guerras e ataques, resta-nos procurar/produzir máquinas de luta (NEGRI; GUATTARI, 2017) engajadas na criação por novos espaços de liberdade. Que podem promover revoluções, em linhas de fuga, em um plano muito mais molecular, como Guattari (1987) ressalta em seus estudos. Uma revolução que vai na direção das mutações do desejo, capaz de pôr em questão toda uma ordem estabelecida, que questiona as relações de exploração e controle da rede socioambiental. É o que buscamos ressaltar ao revisar as produções da máquina desejanteambiental $\left.\right|^{5}$ que podem ensejar pela liberdade de aprendizagem, criação e invenção de currículos nômades ${ }^{6}$ (abertos e flexíveis as criações cotidianas) em conexão com as comunidades-escolas-universidades.

\section{Engendramentos da máquina desejanteambiental: muito além de contrapor/resistir os processos colonizadores da máquina da colonialidade}

Pensar nas possibilidades e criar mundos possíveis em meio aos engendramentos das máquinas colonizadoras é como relacionamos os nomadismos das reexistências na educação ambiental. Assim, um conceito dialogado com Deleuze e Guattari (2011) é o de máquinas.

Segundo os autores, em uma sociedade capitalista ou socialista, a estrutura social pode ser entendida como máquinas, assim ressaltam que as máquinas capitalísticas operam de forma a sustentar o corpo social. De acordo os autores, toda máquina é "máquina de máquinas", pois elas sempre estão em um processo de produção, promovendo desterritorializações, reterritorializações, descodificações.

Deleuze e Guattari (2011) também tecem "diferenças" entre as máquinas molares e as moleculares, apesar do limiar tênue entre seus processos de produção. São molares as máquinas dominantes. Dentre elas, os autores exemplificam citando as máquinas sociais, técnicas ou orgânicas; já as máquinas moleculares são as desejantes.

final de 2019 e início de 2020, com cerca de 27 vítimas humanas e 1 bilhão de animais mortos (TAJRA, 2020); e o estudo publicado também em 2007 (CHENG et al., 2007), que alertava para uma possível pandemia de SARSCoV por meio do consumo humano de animais silvestres - pandemia que ocorre no momento da escrita deste texto, com mais de 182 milhões de casos confirmados no mundo e mais de três milhões e 954 mil (3.954.324) mortos, em 02 de julho de 2021 (WHO, 2021).

${ }^{5}$ Como uma imbricação entre os conceitos (um não pode ser dissociado do outro), ALVES (2001) desenvolve uma concepção com a qual também dialogamos neste texto.

6 O conceito "currículos nômades" partem de uma concepção que os currículos são dinâmicos e abertos às problematizações que os contextualizam, sempre em movimento. 
As máquinas molares possuem engrenagens de dominação e exploração a fim de obter seus "produtos finais". A história da colonização portuguesa no Brasil talvez possa estabelecer relação com essa atuação maquínica nas instituições, em que podem promover territorializações do uno, codificando fluxos colonizadores de poder, de saber e de ser. De acordo com Guattari e Rolnik (1996, p. 38), “É, portanto, num só movimento que nascem os indivíduos e morrem os potenciais de singularização".

Talvez a produção de subjetividades promovida pela máquina molar colonizadora ainda permaneça e atue com seus mecanismos na sociedade, uma vez que essa máquina molar pode atualizar e, ao incorporar as engrenagens da máquina capitalística, o que neste texto atribuímos à máquina da colonialidade, pode manter suas formas de controle em meio às novas tecnologias e/ou a outras formas. Isso porque, segundo os autores:

\footnotetext{
O capitalismo instaura ou restaura todos os tipos de territorialidades residuais e factícias, imaginárias ou simbólicas, sobre as quais ele tenta, bem ou mal, recodificar, reter as pessoas derivadas das quantidades abstratas (DELEUZE; GUATTARI, 2011, p. 53).

O capitalismo se apodera dos seres humanos por dentro. Sua alienação pelas imagens e idéias é apenas um dos aspectos de um sistema geral de servomecanismo de seus meios fundamentais de semiotização, tanto individuais quanto coletivos (GUATTARI, 1987, p. 205).
}

Sobre o servomecanismo, que pode ser engendrado pelo capitalismo na dominação subjetiva, Guattari (1987, p. 206) complementa: "É por intermédio do servomecanismo maquínico que ele se instala no coração dos indivíduos". Em outra obra, ao compor com Deleuze, afirma que, nessa maquinação, “[...] o real não é impossível, ele é cada vez mais artificial" (DELEUZE; GUATTARI, 2011, p. 53), o que nos suscita a problematizar: como se movem os fluxos de reexistências na trama da colonização, onde não somente os corpos são colonizados, mas também os pensamentos?

Nas tentativas de produzir pistas para essa questão, aproximamo-nos novamente de Deleuze e Guattari, que desenvolvem o conceito das máquinas moleculares. Nessas máquinas que, para os autores, são flexíveis e formativas, até suas falhas são funcionais. Elas operam por ligações não localizáveis e por localizações dispersas. São máquinas desejantes por terem como mola propulsora os desejos, funcionam desarranjando-se constantemente e sua 
produção é multiplicidade pura. Entretanto, sempre há possibilidade de cristalizações, como um fascismo "microscópico" (microfascismos) que "[...] se instaura no seio das máquinas desejantes" (GUATTARI, 1987, p. 20).

Nessa perspectiva, imaginamos e pensamos em uma educação ambiental decolonial, que pode operar como uma máquina desejanteambiental, produzindo no e do comum. Enquanto a máquina da colonialidade pode promover processos de "individuação", que Guattari conceitua como a "alienação do desejo" (GUATTARI; ROLNIK, 1996), a máquina desejanteambiental poderia engendrar processos de singularização, que são “[...] processos disruptores no campo da produção do desejo [e] movimentos de protesto do inconsciente" contra a subjetividade capitalística (GUATTARI; ROLNIK, 1996, p. 45).

Nesse sentido, poderíamos imaginar e pensar a potencialidade dos engendramentos da máquina desejanteambiental em reterritorializar o que a máquina da colonialidade desterritorializou... a relação com a terra, com as culturas, os afetos... o desejo de compor os coletivos, os desejos ecocomunitários. Assim, poderíamos problematizar: será que os estudos acadêmicos, ao promoverem conexões com as comunidades buscando novas potências de agir, sentir, imaginar e pensar podem potencializar o atravessamento de uma educação ambiental decolonial?

Em meio a uma formação monocultural, talvez os fluxos descodificados pela máquina desejanteambiental promovam fissuras na composição de currículos, culturas e vivências. Cartografar ${ }^{7}$ esses fluxos de composições curriculares pode nos fornecer pistas para pensar as possibilidades de atravessamentos da educação ambiental.

Guimarães e Sampaio (2014) fazem outro movimento, mas ressaltam a potência na articulação das pesquisas em educação ambiental com os estudos culturais. Para o autor e a autora, essa articulação promove fissuras no dispositivo da sustentabilidade, o que

\footnotetext{
${ }^{7}$ A opção teórico-metodológica pela cartografia parte de um diálogo com Tristão (2013, p. 852), no qual a autora problematiza que "no paradigma dominante da ciência moderna, os fatos precisam ser medidos ou pesados. Mas as relações sociais e humanas com o meio ambiente e uma perspectiva socioecológica da educação e do desenvolvimento não podem ser medidas nem pesadas; podem ser mapeadas ou cartografadas". Assim, concordamos com a autora ao assumir essa mudança na pesquisa em educação ambiental: "em vez de medir, cartografar e narrar".
} 
relacionamos com os engendramentos da máquina desejanteambiental ao descodificar os fluxos colonizadores nos currículos acadêmicos.

Nessa mesma concepção, podemos situar os estudos realizados no núcleo de pesquisa, o NIPEEA/UFES, ${ }^{8}$ no qual se busca uma permanente correlação entre o lugar, as culturas e as produções narrativas locais nas produções acadêmicas.

Os estudos de Tristão (2012) compreendem a educação ambiental em uma concepção que se aproxima da pós-colonial, multicultural, na busca por alternativas aos processos homogêneos de desenvolvimento econômico e cultural que a globalização impôs e generalizou como únicas possibilidades. Segundo a autora:

O monoculturalismo é contrário à ideia ecológica de mundo, porque é sempre uma ideia de força, de uma cultura de guerra em sentido metafórico, o que anula a diversidade de pensamentos e de ações. A valorização das culturas pode ser um meio para construir um futuro sustentável (TRISTÃO, 2012, p. 219).

Nesta pesquisa, acreditamos que podemos observar os engendramentos da máquina desejanteambiental nos estudos de Tristão, ao problematizar a valorização das culturas como forma de favorecer a sustentabilidade, o que também pode nos fornecer pistas. Em nossos estudos, também compreendemos que os movimentos de reexistências, ao promoverem as culturas na escola e na universidade, podem criar possibilidades para a educação ambiental em uma perspectiva decolonial.

Em outro artigo, a autora discorre sobre a importância de compreender como a colonização, seguida da colonialidade, produziu e produz "[...] marcas históricas de assimetrias, de exploração da natureza, de subjugação dos povos colonizados, de dominação das culturas com a imposição do cristianismo e pela imposição civilizadora, desenvolvimentista e intervencionista" (TRISTÃO, 2016, p. 35), para que possamos nos contextualizar, auxiliar na desconstrução dos discursos colonizadores e produzir nossas próprias narrativas.

\footnotetext{
${ }^{8}$ O Núcleo Interdisciplinar de Pesquisas e Estudos em Educação Ambiental (NIPEEA) foi criado em 2005 e emergiu da necessidade de integração entre projetos que envolvem ensino, pesquisa e extensão, com vistas à consolidação de um grupo formado por professoras(es); alunas(os) dos cursos de graduação, do Mestrado e Doutorado em Educação no Programa de Pós-Graduação em Educação (PPGE) da Universidade Federal do Espírito Santo (UFES) e de egressas(os) interessadas(os) (NIPEEA, 2020).
} 
Esses engendramentos decolonizadores também podem ser observados em outro artigo da autora, em parceria com Vieiras, no qual observamos a importância de se analisar a colonialidade e compreender suas formas atualizadas de controle, ${ }^{9}$ para que possamos repensar a educação ambiental. Segundo a autora e o autor:

[...] a Educação Ambiental [...] vem produzindo uma narrativa em seu movimento educativo-ambiental, defendendo que é importante considerar, em suas análises e práticas, as relações com o lugar, com as comunidades e as culturas compartilhadas. Além disso, é preciso reconstruir nosso sentimento de pertencer à natureza em estreita relação com a cultura. Portanto, descolonizar ensejos das dicotomias, das dogmatizações e das essencializações criadas no pensamento colonial moderno são problematizações que nos levam a repensar a EA (TRISTÃO; VIEIRAS, 2017, p. 105).

Dialogando com esse texto, observamos que a autora e o autor desenvolvem seus estudos em uma perspectiva que se aproxima de uma concepção decolonial, ao ressaltarem a potência das reexistências produzidas pelas narrativas, que podem ser carregadas de experiências culturais. Nessa concepção, a educação ambiental pode se mover molecularmente articulada às comunidades que destacam a importância de preservar seus hábitos e costumes ancestrais de vivenciar as culturas locais.

\section{Produções no GT 22 da ANPEd e no Banco da CAPES}

A máquina desejanteambiental pode produzir engendramentos em todos os espaçostempos. ${ }^{10}$ Aqui fazemos um recorte de 2013 a 2018 de algumas produções entre trabalhos apresentados no Grupo de Trabalho de Educação Ambiental (GT 22) das reuniões da Associação Nacional de Pesquisa e Pós-Graduação em Educação (ANPEd) e teses veiculadas no banco da Coordenação de Aperfeiçoamento de Pessoal de Nível Superior (CAPES).

\footnotetext{
9 Segundo Tristão e Vieiras (2017), a colonialidade se relaciona com os processos identitários culturais de dominação e de exploração entre e dentro de regiões; com o modelo dissociativo da sociedade com o meio ambiente por meio das dicotomias criadas pelo pensamento colonial moderno, impondo uma relação de controle dos povos, dos territórios e das culturas; além do controle da natureza promovido pelos processos colonizadores.

${ }^{10}$ Alves (2001) observa o espaçotempo escolar como dimensão material do currículo, composto de relações múltiplas entre múltiplos sujeitos, com saberes múltiplos, que aprendem/ensinam o tempo todo múltiplos conteúdos de múltiplas maneiras.
} 
$\mathrm{Na}$ tentativa de encontrar as produções em educação ambiental nas reuniões nacionais da ANPEd (ANPED, 2020), buscamos publicações do GT 22. Ao pesquisar no banco de dados das reuniões, ${ }^{11}$ que ocorreram no período de 2013 a 2018, encontramos três eventos nacionais nos anos de 2013, 2015 e 2017. Nos anais desses eventos, foram divulgadas 39 pesquisas, mas apenas duas - publicadas nos anais da reunião em 2017 - desenvolveram seus estudos na universidade, a saber:

a) "A temática ambiental nos currículos dos cursos de pedagogia da Uneb", de Vanessa Ribeiro dos Reis (Uneb);

b) "Desafios e aprendizagens da ambientalização em uma universidade", de Maria de Lourdes Spazziani (Unesp).

Entretanto, apesar dos dois textos (REIS, 2017; SPAZZIANI, 2017) tecerem suas pesquisas em educação ambiental nos currículos, ambos partem de uma concepção analítica, por meio de levantamento de dados e análise documental, que se afasta da perspectiva na qual procuramos situar a nossa pesquisa. Nessa mesma concepção analítica, encontramos o texto de Pinheiro (2017) nos anais dessa reunião, em que o autor desenvolve sua pesquisa em uma escola municipal.

Dos estudos que não são ambientados na universidade, encontramos dois artigos apresentados na reunião de 2013 - que abordam a cultura nos atravessamentos curriculares em uma concepção mais próxima do que buscamos. Ressaltamos que ambas as pesquisas foram desenvolvidas no núcleo de pesquisa - NIPEEA/UFES:

a) "Educação ambiental entre práticas culturais cotidianas dos Mascarados do Congo", de Andreia Teixeira Ramos;

b) “Educação ambiental autopoiética entre manguezais, redes cotidianas escolares e práticas pesqueiras", de Soler Gonzalez.

O objeto de Ramos (2013) foi acompanhar processos da produção dos Mascarados do Congo, entre fluxos, encontros, conversas, linhas, formas e forças. A autora deixa-se ser atravessada por elas. Já Gonzalez (2013a) investigou como os saberes socioambientais

\footnotetext{
${ }^{11}$ Nessa revisão, não foi necessário alocar palavras-chave devido a quantidade razoável de trabalhos publicados (39). Os trabalhos foram selecionados após a leitura dos resumos e, posteriormente, a leitura na íntegra.
} 
influenciam as práticas do bairro, as escolas e os manguezais de uma comunidade pesqueira, movida pelo "calor cultural" do Turismo Gastronômico e da Semana Santa.

Essas pesquisas fluem em diálogo com Maturana, na criação de uma educação ambiental autopoiética, ${ }^{12}$ que articula as culturas locais nas composições curriculares. Relacionamos que os fluxos decolonizadores desses estudos podem produzir reexistências nas estruturas da educação.

Também observamos essas conexões em dois artigos que buscam cartografar reexistências nas reuniões de 2015 e 2017:

a) "As táticas de re-existência no enfrentamento dos conflitos socioambientais no Estado de Mato Grosso - Brasil", de Michelle Jaber e Regina Silva da Universidade Federal do Mato Grosso (UFMT);

b) "Resistências e relações de poder na produção cotidiana da educação ambiental: uma problematização atravessada pelo crime socioambiental na Bacia do Rio Doce", de Rosinei Ronconi Vieiras (UFES).

Ambos os artigos desenvolvem problematizações em um campo de enfrentamentos e tensões, o que relacionamos com a potência na criação das reexistências que não se assujeitam aos fluxos colonizadores da máquina da colonialidade (representados pelas empresas de minério e agronegócio, nas pesquisas de Vieiras e Jaber e Silva, respectivamente).

Vieiras (2017a), que também realizou sua pesquisa no NIPEEA/UFES, cartografa esses movimentos entre estudantes do Instituto Federal do Espírito Santo (IFES), campus Colatina, dialogando com Foucault, enquanto Jaber e Silva (2015) os encontra em grupos sociais no Mato Grosso, dialogando com Certeau e Freire, principalmente.

Nas tentativas de buscar uma conexão desses estudos com nossa pesquisa, problematizamos que, talvez, o desejo desses movimentos por justiça e as narrativas

\footnotetext{
12 Autopoiese é um conceito desenvolvido pelos biólogos e filósofos chilenos Francisco Varela e Humberto Maturana para compreender a capacidade dos seres vivos de produzir a si próprios: “É uma explicação do que é o viver e, ao mesmo tempo, uma explicação da fenomenologia observada no constante vir-a-ser dos seres vivos no domínio de sua existência" (MATURANA, 2001, p. 12).
} 
produzidas criem pistas que sugerem a criação de mundos possíveis diante de crimes e conflitos socioambientais.

Além da criação dos mundos possíveis, ressaltamos os efeitos molarmoleculares que podem ocorrer por onde esses fluxos passam. Assim, prosseguimos a pesquisa dentre as dissertações e teses veiculadas no banco da CAPES.

Na pesquisa no Banco de Dissertações e Teses da CAPES (CAPES, 2020), inicialmente realizamos uma busca geral com o seguinte título: “Educação ambiental na universidade"13 _ área de concentração: Educação, com refinamento por data entre os anos de 2013 a 2018. Foram localizadas três teses de doutorado e nenhuma dissertação de mestrado, a saber:

a) a tese de 2014: “Educação ambiental, toque terapêutico e esquizoanálise: um cuidado anti-iatrogênico na enfermagem hospitalar" - defendida por Aline Cristina Calcada Oliveira na Universidade Federal de Rio Grande (FURG);

b) a tese de 2016: "A rosa dos ventos da educação ambiental: reflexões sobre os lugares e perspectivas de educação ambiental na Universidade Federal do Ceará" - defendida por Jose Maclecio de Sousa na Universidade Federal do Ceará (UFC);

c) a tese de 2017: "Naturalismo poético-pampeano: uma potência musical do pensar" defendida por Virginia Tavares Vieira na FURG.

Essas três teses, em diferentes concepções, investigam educações ambientais nos mais diversos contextos: seja na mata atlântica, seja em um hospital-acadêmico (OLIVEIRA, 2014), seja em uma universidade (SOUSA, 2016), seja em músicas (VIEIRA, 2017).

Em uma concepção mais próxima ao que buscamos, Oliveira (2014) desenvolve sua tese articulando a Esquizoanálise de Deleuze e Guattari com experimentações socioambientais vivenciadas pela autora nos contextos da mata atlântica e nos espaços acadêmico e hospitalar de um Hospital Universitário. Na tentativa de buscar conexões com a nossa pesquisa, associamos que os fluxos desejantes da autora podem fluir ao buscar maneiras de minimizar a iatrogenia hospitalar - efeitos colaterais que decorrem dos

\footnotetext{
${ }^{13}$ Inicialmente a pesquisa procurava investigar como a educação ambiental poderia atravessar a universidade, por isso a escolha desse título.
} 
atendimentos médicos - nas práticas da enfermagem, e encontram, por meio do toque terapêutico e da escuta sensível, suas pistas para compor a cartografia.

Também nessa concepção, Vieira (2017) desenvolve sua tese. Em seus estudos, observamos que os desejos podem fluir em ondas musicais por meio de uma educação ambiental mais molecular, buscando pesquisar que relações gaúcho/natureza se produzem na música do Rio Grande Sul, a partir de Foucault. Para sua pesquisa, a autora analisa músicas que entremeiam um modo de olhar e se relacionar com a paisagem natural e cultural, refletindo sobre essas relações e as diferentes leituras que podem ser feitas delas.

Já Sousa (2016) desenvolve sua tese em uma concepção que se aproxima da perspectiva crítica - com distanciamentos do que buscamos -, dialogando com os trabalhos de Paulo Freire. Em seu texto, o autor procura conhecer as experiências da educação ambiental e as ressonâncias na universidade do Ceará. Em nossa leitura, associamos que os fluxos produzidos pela pesquisa podem se cristalizar diante da classificação de lugares delimitados onde ocorrem as experiências ambientais. Ao determinar lugares, talvez possa haver a exclusão de tantas outras possibilidades por onde a educação ambiental se esgueira e foge, como nos deparamos em nossa pesquisa.

Apesar da aproximação das teses de Oliveira (2014) e Vieira (2017) com a abordagem que buscamos da educação ambiental, vários distanciamentos persistem quanto às questões teórico-metodológicas abordadas nesta pesquisa, assim como se distanciam da tese defendida por Sousa (2016) que, além dessas questões, apresenta uma perspectiva da educação ambiental que não dialoga com a que buscamos nos aproximar.

Ao colocarmos essa questão de diferenças de posição, queremos ressaltar que não se trata de pôr uma perspectiva contra a outra, ou mostrar superioridade de uma em frente a outra. A questão é que, na emergência em que vivemos, acreditamos, assim como Stengers (2015), Negri e Guattari (2017) que já não basta questionar/criticar/protestar/classificar e lutar contra, mas é preciso compor com possibilidades de resposta de criação/produção, como destacam os autores:

É no mesmo continuum de lutas contra a exploração e por alternativas positivas que a exploração capitalista e/ou socialista do tempo será cada vez mais questionada e 
[...] um novo tipo de organização comunitária das forças sociais produtivas se iniciará (NEGRI; GUATTARI, 2017, p. 77).

Além disso, no apêndice da obra, Carta arqueológica, Negri nos auxilia a compor esse pensamento para as práticas sociais, ao problematizar que:

[...] a prática social não pode ser somente um pensamento da crítica social, somente um pensamento da crise. Ela deve também tocar a dimensão ontológica e desenvolver a tendência constitutiva.

[...] porque a ruptura abre grande possibilidade de expressão. A prática social revelase como exercício de liberação dos segmentos desejantes (NEGRI; GUATTARI, 2017, p. 164).

Após essa primeira pesquisa mais geral, na tentativa de buscar mais trabalhos, realizou-se uma nova pesquisa no Banco de Dissertações e Teses da CAPES, selecionando os termos: "Educação-Ambiental AND ensino-superior OR universidade"; "Educação-Ambiental AND colonialidade OR pós-colonial"; "Educação-Ambiental AND Deleuze AND Guattari"; "Educação-Ambiental AND resistências OR (re)existências"; "Educação-Ambiental AND cartografia"; "Educação-Ambiental AND desejo"; "Educação-Ambiental AND coletivosestudantis OR movimentos-sociais"; "Educação-Ambiental AND produções-curriculares"; "Educação-Ambiental AND narrativas”; "Educação-Ambiental AND Maturana AND redes-deconversações".

Muitos trabalhos foram encontrados nessas diferentes buscas. Entretanto, observamos que a maioria dos trabalhos ambientados na universidade se aproximam de uma abordagem que se afasta da que buscamos nesta pesquisa - assim como o trabalho de Sousa (2016) - e analisam a sustentabilidade acadêmica por meio de entrevistas e atendimento às legislações.

De outra maneira, ao considerar os trabalhos que não são ambientados na universidade, foram encontradas algumas teses em educação ambiental em uma concepção mais próxima da que propomos em nossa pesquisa. Além disso, problematizamos sobre as possibilidades de potência da educação ambiental nas pesquisas em conexão com as comunidades e culturas locais, como as seis teses produzidas no Núcleo de Pesquisa (NIPEEA/UFES), a saber: 
a) as teses de 2013: 1 - "Estudos culturais em educação ambiental: os usos e consumos dos produtos culturais em espaços na/da biorregião do Caparaó Capixaba" (defendida por Flávia Nascimento Ribeiro); 2 - "Educação ambiental autopoiética com as práticas do bairro Ilha das Caieiras entre os manguezais e as escolas" (defendida por Soler Gonzalez);

b) a tese de 2014: "Gira-mundos: a educação ambiental no mito e o mito na educação ambiental" (defendida por Katia Goncalves Castor);

c) as teses de 2016: 1 - "Sustentabilidades praticadaspensadas: lampejos de pirilampos das escolas de dificílimo acesso de Duque de Caxias/RJ" (defendida por Patricia Raquel Baroni); 2 - "Educação ambiental em suas práticas singulares sustentáveis no processo osmótico comunidadeescola" (defendida por Marcia Moreira de Araújo);

d) a Tese de 2017: "Educação ambiental e biopotência como processos interconstituintes: potencializando outros modos de existência" (defendida por Rosinei Ronconi Vieiras).

Na leitura dessas teses, relacionamos que as pesquisas podem fluir através de linhas de desterritorialização/reterritorialização, buscando conexões com as culturas locais, em diferentes tessituras pós-críticas, que dialogam com Deleuze, Guattari, Foucault, Certeau, Santos e Tristão.

Ribeiro (2013), Gonzalez (2013b), Castor (2014), Baroni (2016), Araújo (2016) e Vieiras (2017b) desenvolvem as suas pesquisas utilizando cartografias que articulam currículos, que são produzidos coletivamente, com os costumes, rituais, festas culturais e crimes ambientais, que atravessam a formação, compondo, assim, currículos dinâmicos e singulares.

Baroni (2016) e Vieiras (2017b) buscam cartografar os movimentos de resistências criados no contexto escolar. Baroni (2016) problematiza as lutas pela sobrevivência nas escolas de difícil acesso em Duque de Caxias/RJ, observando que elas são tecidas como subversões em um modelo que as subalterniza, mas, ao mesmo tempo em que a autora observa processos de invisibilização, encontra também as redes de solidariedade que emergem da educação ambiental, destacando sua potência ecopolítica. 
Já Vieiras (2017b) investiga esses movimentos no campus de Colatina do IFES, observando a produção de subjetividades impetradas pelo capitalismo nas composições curriculares. Em sua pesquisa, trata do atravessamento do crime ambiental ocorrido na barragem de Mariana/MG, encontrando uma educação ambiental produzida e mobilizada a partir de uma rede de afetos que deseja ser potencializada.

Em conexão com as comunidades, em um processo osmótico em que podem fluir os saberes e fazeres, podemos situar as pesquisas de Ribeiro (2013), Gonzalez (2013b), Castor (2014) e Araújo (2016).

Ribeiro (2013) investiga os sujeitos praticantes das localidades de Patrimônio da Penha e Pedra Menina/ES, procurando compreender como os produtos culturais em educação ambiental são traduzidos na produção de narrativas e formação de identidades a partir dos processos sociais, político e das relações de poder. Já Gonzalez (2013b) acompanha os movimentos dos praticantes e narradores da maré da pesquisa (pescadores, desfiadeiras de siris, catadores de caranguejos, comerciantes, estudantes, professoras e professores), seguindo as redes de conversações e defendendo as potências das singularidades dos diferentes contextos comunitários e escolares, que podem possibilitar uma educação ambiental múltipla.

Nessa mesma concepção, a aposta metodológica de Castor (2014) consistiu em criar estratégias de narrar experiências da educação ambiental nos Terreiros de Umbanda e na escola, que promovem conexões por meio das orixalidades, na busca de zonas de confiança e na invenção de encontros mais solidários, por escutas mais sutis, híbridas e de novos sentidos de alianças com maior abertura às lógicas silenciadas historicamente.

Araújo (2016) problematiza a relação de algumas comunidades locais dos municípios da região Sul Capixaba - a situação social e as práticas de gestores ambientais e docentes perante a instalação de grandes empreendimentos de cunho exploratório no meio natural que afetam a dinâmica socioambiental na localidade. A autora discute possibilidades de compreender como as práticas singulares acontecem em processos de singularização, por meio da formação dos gestores, docentes e discentes em seus locus de atuação, numa cartografia desses saberesfazerespoderes em educação ambiental. 
As cartografias produzidas nas pesquisas apresentadas acompanham as redes de conversações que ocorrem naturalmente nos mais variados ambientes. Podemos relacionar essa opção teórico-metodológica com a tentativa de acompanhar os fluxos de afetos e desejo que atravessam os seres humanos e podem ser demonstrados em diferentes formas das conversações, como afirma Maturana (2001).

Ao prosseguir com esta pesquisa dentre as teses que se aproximam mais da concepção que buscamos, encontramos duas produzidas no Grupo Pesquisador em Educação Ambiental, Comunicação e Arte (GPEA) ${ }^{14}$ da UFMT, a saber:

a) a tese de 2013: "Cartografia de Joselândia: o acontecimento e o pensamento da multiplicidade" (defendida por Maria Liete Alves Silva);

b) a tese de 2015: "Currículos festeiros de águas e outonos: fenomenologia da educação ambiental pós-crítica" (defendida por Lucia Shiguemi Izawa Kawahara).

Kawahara (2015) e Silva (2013) tecem suas teses em uma mesma concepção que o NIPEEA/UFES, que associamos aos engendramentos moleculares e menores ${ }^{15}$ da educação ambiental, em conexão com as culturas locais. No desenvolvimento de suas pesquisas, Kawahara (2015) dialoga com Certeau, Maturana, Sato e Tristão, enquanto Silva (2013) interage com Deleuze e Guattari.

Kawahara (2015) utiliza, como palcos investigativos, os contextos das festas tradicionais das comunidades banhadas pelas águas do Pantanal mato-grossense do Brasil e das festas da colheita de arroz celebradas no outono na Ilha de Noto no Japão, empregando a fenomenologia da educação ambiental pós-crítica como opção político-metodológica. A autora faz uma cartografia do imaginário, buscando conhecer as relações e os saberes

\footnotetext{
${ }^{14} \mathrm{O}$ Grupo Pesquisador em Educação Ambiental, Comunicação e Arte (GPEA) possui diversas experiências de pesquisa com vivências nos três biomas do Estado do Mato Grosso (Amazônia, Pantanal e Cerrado), com foco na educação popular, especialmente com pequenas comunidades, considerando suas ofertas escolares. A partir de 2014, o grupo tem se dedicado à crise climática, envolvendo pessoas com deficiências, quilombolas, indígenas, mulheres negras, crianças, professores, adolescentes, LGBTQ+, pescadores, mariscadoras, rendeiras, pequenos agricultores e diversos migrantes, entre outros grupos relacionados com o contexto de justiça climática (GPEA, 2020).

15 O conceito "menor" é articulado a partir da leitura de Deleuze e Guattari do pensamento de Kafka: "Uma literatura menor não é a de uma língua menor, mas antes a que uma minoria faz em uma língua maior" (DELEUZE; GUATTARI, 1977, p. 25).
} 
construídos nas festas tradicionais como alternativa para pensar, fazer e viver a educação ambiental para além da escola, compondo um currículo da vida.

Silva (2013) desenvolve sua tese com os conhecimentos das áreas úmidas do Pantanal mato-grossense, gerados no contexto do Instituto Nacional de Ciência e Tecnologia em Áreas Úmidas (Inau/UFMT), e com os conhecimentos locais de Joselândia, distrito de Barão de Melgaço/MT, realizando também agenciamentos educomunicativos na Escola Estadual Maria Silvino Peixoto de Moura, em São Pedro de Joselândia. A autora articula suas considerações sobre a interface educomunicação e educação ambiental, na perspectiva dos temas transversais potencialmente contextualizadores e favorecedores de uma educação da multiplicidade, que a autora relaciona com o rizoma, dialogando com Deleuze e Guattari.

Assim como Silva (2013), apostamos em uma educação ambiental rizomática, em suas articulações nos diferentes contextos, em zonas de intensidade contínua, seja na instituição, seja na comunidade. Em nossos estudos, problematizamos se os movimentos de reexistências podem se articular como rizomas e explorar novas conexões que não se limitam a nenhuma barreira conceitual ou física.

Outra tese que se aproxima da perspectiva que buscamos foi produzida no Programa de Pós-Graduação em Educação Ambiental da FURG:

a) a tese de 2013: "Por uma educação ambiental biorizomática: cartografando devires e clinamens através de processos de criação e poéticas audiovisuais" (defendida por Claudio Tarouco de Azevedo).

Azevedo (2013) tece sua tese na perspectiva de Guattari, promovendo o caminho cartográfico de sua pesquisa numa perspectiva epistemológica fundamentada na Análise Institucional e na Esquizoanálise. Utiliza um diário de pesquisa, questionários, fotografias e recursos audiovisuais, oficinas e exposições artísticas interventivas para promover a produção dos dados com os grupos envolvidos, assim como uma intervenção final em um abrigo de menores. $\mathrm{O}$ autor defende que os diversos devires e clinamens potencializados ao longo da pesquisa, cartografados durante o processo, assim como as produções audiovisuais e as oficinas inventadas, constituem-se em resultados fundamentais na promoção dessa educação ambiental para o cuidado, a alteridade e a solidariedade no rizoma da vida. 
Em meio à potência dessas pesquisas e as aproximações do que defendemos, continuamos a buscar os fluxos de desejo que se entrelaçam aos nossos estudos.

\section{Considerações finais}

No diálogo com esses textos, acreditamos que as resistências criadas, no contexto da colonialidade, não se limitam a "lutar contra", mas reexistem em fluxos de produção, criação e se potencializam por meio das singularidades.

Assim, nossa aposta é no atravessamento de uma educação ambiental decolonial, múltipla, nômade e revolucionária que, imbricada às micropolíticas comunitárias, pode potencializar currículos nômades. Aquela que se articula com os movimentos sociais e com a cultura local, tece fluxos de produção curricular e que reexiste nas instituições de ensino, mesmo que tentem estrangulá-la em disciplinas e ações esporádicas. A maioria de suas ressonâncias são informais e transgressoras. Nem mesmo a sua ausência nos currículos é capaz de impedir os fluxos decolonizados pela máquina desejanteambiental.

A educação ambiental, em uma perspectiva decolonial, pode promover fluxos que se articulam aos espaçostempos das comunidades-escolas-universidades e para além delas, pois é maquínica, transversal e multidimensional. É como uma máquina desejanteambiental, engendrando fluxos desejosos de naturezasculturas.

É essa educação ambiental decolonial que procuramos ressaltar neste texto, uma máquina desejante que pode engendrar linhas de fuga em meio ao poder axiomático da máquina da colonialidade. Uma máquina desejanteambiental que pode, talvez, ser potencializada pelos estudos em conexão com as comunidades, como os que pesquisamos. Produções que podem potencializar as máquinas de luta em meio a um contexto de desmonte e tentativas de controle pela máquina da colonialidade, lutando por novos espaços de liberdade, seja nas instituições, seja fora delas. Pesquisas que compõem currículos nômades com as comunidades, potencializando ações e sentimentos, que buscam recriar relações que foram descodificadas ao longo dos tempos. Relações de composição, colaboração e alegria.

\section{Referências}


ALVES, Nilda. Imagens das escolas: sobre redes de conhecimentos e currículos escolares.

Educ. Rev. [on-line], n.17, p. 53-62, 2001.

ARAÚJO, Marcia Moreira de. Educação ambiental em suas práticas singulares sustentáveis no processo osmótico comunidadeescola. 2016. Tese (Doutorado em Educação) Universidade Federal do Espírito Santo, Vitória, 2016.

ASSOCIAÇÃO NACIONAL DE PÓS-GRADUAÇÃO E PESQUISA EM EDUCAÇÃO (ANPED). Reuniões científicas nacionais. Disponível em: http://www.anped.org.br/reunioescientificas/nacional. Acesso em: 8 abr. 2020.

AZEVEDO, Claudio Tarouco de. Por uma educação ambiental biorizomática: cartografando devires e clinamens através de processos de criação e poéticas audiovisuais. 2013. Tese (Doutorado em Educação Ambiental) - Universidade Federal do Rio Grande, Rio Grande, 2013.

BARONI, Patricia Raquel. Sustentabilidades praticadaspensadas: lampejos de pirilampos das escolas de dificílimo acesso de Duque de Caxias/RJ. 2016. Tese (Doutorado em Educação) Universidade Federal do Espírito Santo, Vitória, 2016.

CASTOR, Katia Goncalves. Gira-mundos: a educação ambiental no mito e o mito na educação ambiental. 2014. Tese (Doutorado em Educação) - Universidade Federal do Espírito Santo, Vitória, 2014.

CHENG, Vincent C. C.; LAU, Susanna K. P.; WOO, Patrick C. Y.; YUEN, Kwok Yung. Severe Acute Respiratory Syndrome Coronavirus as an Agent of Emerging and Reemerging Infection.

Clinical Microbiology Reviews, v. 20, n. 4, p. 660-694, out. 2007.

COORDENAÇÃO DE APERFEIÇOAMENTO DE PESSOAL DE NÍVEL SUPERIOR (CAPES). Catálogo de teses e dissertações. Disponível em: https://catalogodeteses.capes.gov.br/catalogoteses/\#!/. Acesso em: 8 abr. 2020.

DELEUZE, Gilles; GUATTARI, Félix. Kafka: por uma literatura menor. Rio de Janeiro: Imago, 1977.

DELEUZE, Gilles; GUATTARI, Félix. 0 anti-édipo: capitalismo e esquizofrenia. Tradução de Luiz B. L. Orlandi. 2. ed. São Paulo: Editora 34, 2011.

GONZALEZ, Soler. Educação ambiental autopoiética entre manguezais, redes cotidianas escolares e práticas pesqueiras. Trabalho apresentado no GT 22. 36a Reunião Nacional da Associação Nacional de Pós-Graduação e Pesquisa em Educação, realizada de 29 de setembro a 2 de outubro de 2013, na Universidade Federal de Goiás, campus Samambaia, Goiânia/GO, 2013a. 
GONZALEZ, Soler. Educação ambiental autopoiética com as práticas do bairro Ilha das Caieiras entre os manguezais e as escolas. 2013. Tese (Doutorado em Educação) Universidade Federal do Espírito Santo, Vitória, 2013b.

GRUPO PESQUISADOR EM EDUCAÇÃO AMBIENTAL, COMUNICAÇÃO E ARTE (GPEA). Histórico. Disponível em: https://gpeaufmt.blogspot.com/p/historico.html. Acesso em: 11 jun. 2020.

GUATTARI, Félix. Revolução molecular: pulsações políticas do desejo. Tradução de Suely Belinda Rolnik. 3. ed. São Paulo: Editora Brasiliense, 1987.

GUATTARI, Félix; ROLNIK, Suely. Micropolítica: cartografias do desejo. 4. ed. Petrópolis: Vozes, 1996.

GUIMARÃES, Leandro Belinaso; SAMPAIO, Shaula Maíra Vicentini de. Educação ambiental nas pedagogias do presente. Em Aberto, Brasília, v. 27, n. 91, p. 123-134, jan./jun. 2014.

JABER, Michelle; SILVA, Regina. As táticas de re-existência no enfrentamento dos conflitos socioambientais no Estado de Mato Grosso - Brasil. Trabalho apresentado no GT 22. 37a Reunião Nacional da Associação Nacional de Pós-Graduação e Pesquisa em Educação, realizada de 4 a 8 de outubro de 2015, na Universidade Federal de Santa Catarina, campus Florianópolis, Florianópolis/SC, 2015.

KAWAHARA, Lucia Shiguemi Izawa. Currículos festeiros de águas e outonos: fenomenologia da educação ambiental pós-crítica. 2015. Tese (Doutorado em Educação) - Universidade Federal de Mato Grosso, Cuiabá, 2015.

LI, Ruiyun; PEI, Sen; CHEN, Bin; YIMENG, Song; ZHANG, Tao; YANG, Wan; SHAMAN, Jeffrey. Substantial undocumented infection facilitates the rapid dissemination of novel Coronavirus (SARS-CoV-2). Science, v. 368, n. 6490, p. 489-493, 01 may 2020.

MATURANA, Humberto. Cognição, ciência e vida cotidiana. Organização e tradução de Cristina Magro e Victor Paredes. Belo Horizonte: Ed. UFMG (Humanitas), 2001.

NEGRI, Antônio; GUATTARI, Felix. As verdades nômades: por novos espaços de liberdade. Tradução de Mario Antunes Marino e Jefferson Viel. São Paulo: Autonomia Literária e Editora Politeia, 2017.

NÚCLEO INTERDISCIPLINAR DE PESQUISA E ESTUDO EM EDUCAÇÃO AMBIENTAL (NIPEEA). Sobre o NIPEEA. Disponível em: http://nipeea.blogspot.com/p/historico.html. Acesso em: 11 jun. 2020.

OLIVEIRA, Aline Cristina Calcada. Educação ambiental, toque terapêutico e esquizoanálise: 
um cuidado anti-iatrogênico na enfermagem hospitalar. 2014. Tese (Doutorado em Educação Ambiental) - Universidade Federal de Rio Grande, Rio Grande, 2014.

PINHEIRO, Márcio Fernando Duarte. Educação ambiental e currículo: um estudo em uma escola municipal de Tracuateua - PA. Trabalho apresentado no GT 22. 38a Reunião Nacional da Associação Nacional de Pós-Graduação e Pesquisa em Educação, realizada de 10 a 5 de outubro de 2017, na Universidade Federal do Maranhão, campus Dom Delgado, São Luís/MA, 2017.

RAMOS, Andreia Teixeira. Educação ambiental entre práticas culturais cotidianas dos Mascarados do Congo. Trabalho apresentado no GT 22. 36a Reunião Nacional da Associação Nacional de Pós-Graduação e Pesquisa em Educação, realizada de 29 de setembro a 2 de outubro de 2013, na Universidade Federal de Goiás, campus Samambaia, Goiânia/GO, 2013.

REIS, Vanessa Ribeiro dos. A temática ambiental nos currículos dos cursos de pedagogia da Uneb. Trabalho apresentado no GT 22. 38a Reunião Nacional da Associação Nacional de Pós-Graduação e Pesquisa em Educação, realizada de 1 ㅇa 5 de outubro de 2017, na Universidade Federal do Maranhão, campus Dom Delgado, São Luís/MA, 2017.

RIBEIRO, Flávia Nascimento. Estudos culturais em educação ambiental: os usos e consumos dos produtos culturais em espaços na/da biorregião do Caparaó Capixaba. 2013. Tese (Doutorado em Educação) - Universidade Federal do Espírito Santo, Vitória, 2013.

SILVA, Maria Liete Alves. Cartografia de Joselândia: o acontecimento e o pensamento da multiplicidade. 2013. Tese (Doutorado em Educação) - Universidade Federal de Mato Grosso, Cuiabá, 2013.

SOUSA, Jose Maclecio de. A rosa dos ventos da educação ambiental: reflexões sobre os lugares e perspectivas de educação ambiental na Universidade Federal do Ceará. 2016. Tese (Doutorado em Educação) - Universidade Federal do Ceará, Fortaleza, 2016.

SPAZZIANI, Maria de Lourdes. Desafios e aprendizagens da ambientalização em uma universidade. Trabalho apresentado no GT 22. 38a Reunião Nacional da Associação Nacional de Pós-Graduação e Pesquisa em Educação, realizada de 1 a 5 de outubro de 2017, na Universidade Federal do Maranhão, campus Dom Delgado, São Luís/MA, 2017.

STENGERS, Isabelle. No tempo das catástrofes: resistir à barbárie que se aproxima. Tradução de Eloisa Araújo Ribeiro. São Paulo: Cosac Naify, 2015.

TAJRA, Alex. Austrália foi alertada há 13 anos pela ONU sobre aumento de queimadas. UOL, São Paulo, 12 jan. 2020. Notícias. Meio ambiente. Disponível em:

https://noticias.uol.com.br/meio-ambiente/ultimas-noticias/redacao/2020/01/12/australiafoi-alertada-ha-mais-de-10-anos-sobre-aumento-de-queimadas.htm. Acesso em: 11 jun. 2020. 
TRISTÃO, Martha. A educação ambiental e a emergência de uma cultura sustentável no cenário da globalização. R. Inter. Interdisc. INTERthesis, Florianópolis, v. 9, n.1, p. 207-222, jan./jul. 2012.

TRISTÃO, Martha. Educação ambiental e a descolonização do pensamento. Rev. Eletrônica Mestr. Educ. Ambient., p. 28-49, jul. 2016. Edição especial.

TRISTÃO, Martha; VIEIRAS, Rosinei Ronconi. Decolonizar o pensamento: apontamentos e entrelaçamentos epistêmicos com a educação ambiental. Rev. Eletrônica Mestr. Educ. Ambient. Rio Grande, XVI Encontro Paranaense de Educação Ambiental, p. 103-117, set. 2017. Edição especial.

VIEIRA, Virginia Tavares. Naturalismo poético-pampeano: uma potência musical do pensar. 2017. Tese (Doutorado em Educação Ambiental) - Universidade Federal do Rio Grande, Rio Grande, 2017.

VIEIRAS, Rosinei Ronconi. Resistências e relações de poder na produção cotidiana da educação ambiental: uma problematização atravessada pelo crime socioambiental na Bacia do Rio Doce. Trabalho apresentado no GT 22. 38a Reunião Nacional da Associação Nacional de Pós-Graduação e Pesquisa em Educação, realizada de 1ㅇ a 5 de outubro de 2017, na Universidade Federal do Maranhão, campus Dom Delgado, São Luís/MA, 2017 a.

VIEIRAS, Rosinei Ronconi. Educação ambiental e biopotência como processos interconstituintes: potencializando outros modos de existência. 2017. Tese (Doutorado em Educação) - Universidade Federal do Espírito Santo, Vitória, 2017b.

WORLD HEALTH ORGANIZATION (WHO). Rolling updates on Coronavirus disease (COVID-19). Disponível em: https://www.who.int/emergencies/diseases/novel-coronavirus-2019/eventsas-they-happen. Acesso em: 10 jun. 2020.

WORLD HEALTH ORGANIZATION (WHO). WHO Coronavirus Disease (COVID-19) Dashboard. Disponível em: https://covid19.who.int/. Acesso em: 2 jul. 2021.

Submetido em: 17-12-2020.

Publicado em: 20-08-2021. 